\title{
Operator eye doses during Computed Tomography Fluoroscopic lung biopsy
}

Ernest U. Ekpo ${ }^{\text {ac }}$, Suleman Bakhshi ${ }^{\mathrm{a}}$, Elaine Ryan ${ }^{\mathrm{a}}$, Peter $\operatorname{Hogg}^{\mathrm{b}}$, and Mark F. McEntee ${ }^{\mathrm{a}}$

a. Discipline of Medical Radiation Science, Faculty of Health Sciences, The University of Sydney.

b. Directorate of Radiography, University of Salford, UK and Karolinska Institute, Sweden.

c. Department of Radiography and Radiology, University of Calabar, Nigeria

\section{Conflict of interest: None}

Funding: None

\section{Corresponding Author:}

ERNEST U. EKPO| Discipline of Medical Radiation Science

Faculty of Health Sciences | Brain \& Mind Centre

The University Of Sydney

M205 | 75 East St Lidcombe | NSW2141

$\mathrm{T}+61403002413$

E ernest.ekpo@sydney.edu.au | eekp9437@uni.sydney.edu.au 


\section{ABSTRACT}

Aims: To examine the peak entrance surface air kerma (peak ESAK) to the eyes during CT fluoroscopy lung biopsy, and the impact of lead glasses, exposure parameters, head rotation, and height on peak ESAK to the eyes.

Methods: Two phantoms simulating the patient and radiologist were used, and 108 exposures were made using a 16-slice Toshiba Alexion CT scanner (Toshiba Medical Systems, Nasu, Japan). ESAK to the phantom radiologist's right eye were measured using an Unfors $\mathrm{Xi}$ Dosimeter (RaySafe, Billdal, Sweden) with and without lead glasses at two kilovoltages (120 $\mathrm{kVps}$ and $135 \mathrm{kVps})$ and three $\mathrm{mA}$ settings $(10 \mathrm{~mA}, 20 \mathrm{~mA}$, and $30 \mathrm{~mA}$. A paired t-test was used to compare peak ESAK to the eye at different, angles, heights, and $\mathrm{kVps}$ and $\mathrm{mAs}$ with and without lead glasses.

Results: Peak ESAK was higher without compared to with lead glasses $(p \leq 0.001)$. The peak ESAK to the eyes increased as the phantom radiologist rotates toward the gantry without lead glasses, from $2.42 \mu \mathrm{Gy}$ at $120^{\circ}$ to $10.54 \mu \mathrm{Gy}$ at $30^{\circ}(\mathrm{p}=0.001)$. No significant difference was noted in peak ESAK with change in phantom radiologist height $(\mathrm{p}>0.05)$. Increase from $120 \mathrm{kVp}$ to $135 \mathrm{kVp}$ resulted in $23 \%$ and $26 \%$ increases in peak ESAK with and without lead glasses respectively $(\mathrm{p}=0.001)$. Increase of tube current from $10 \mathrm{~mA}$ to $20 \mathrm{~mA}$ almost doubled peak $\operatorname{ESAK}(\mathrm{p}=0.005)$.

Conclusion: Findings demonstrate that lead glasses reduce ESAK to the eyes, and that increased $\mathrm{kVp}, \mathrm{mA}$, and eye rotation to the gantry increases ESAK to the eyes.

Keywords: ESAK; radiation risk; radiation protection; radiation monitoring; interventional radiology 


\section{INTRODUCTION}

Medical imaging is a technologically driven field that is constantly evolving. Advances in technological innovations are aimed at improving the diagnosis of disease processes and guiding of interventional techniques [1]. Introduction of Computed Tomography (CT) into the medical imaging world revolutionized interventional radiological procedures. The first-ever CT guided biopsy was performed in 1975, and since then CT has been regarded as the optimal imaging tool for guiding interventional procedures such as lung and liver biopsies [2, 3]. Prior to 1994, CT guided biopsies were performed with continuous re-positioning of the needle during scanning [4]. CT guided biopsy was revolutionized in 1994 with the development of CT Fluoroscopy (CTF). With CTF, images are reconstructed and displayed in real time [5], allowing radiologists to visualize needle location during an interventional procedure. Thus, CTF has facilitated quicker and easier performance of interventional procedures [6], however, it exposes radiologists to scattered radiation from such procedures [7].

Ionizing radiation, regardless how small, has the potential to cause damage to biological tissues, with the potential biological effects related to the amount of radiation reaching such tissue [8]. CTF is associated with high radiation dose, and has been shown to produce a mean CT dose Index (CTDI) about 12 times higher than that of Multi-Slice Computed Tomography (MSCT) during lung biopsies [6]. To minimize the effect CTF doses on radiologists' high intensity regions such as the hands, dose reduction techniques have been proposed. These dose reduction techniques include lead aprons, thyroid shields, and lead glasses as well as approaches such as needle holders, and quick check methods $[9,10]$. 
Of these high intensity regions, the lens of the eye is considered one of the most radiosensitive structures in the human body [11]. The 2011 ICRP publication 118 affirms that low doses of radiation has the potential to cause cataracts [12], highlighting a need for protection of the lens during CTF. The ICRP has set dose limits of $20 \mathrm{mSv}$ per year over 5 years for the lens, with a maximum of $50 \mathrm{mSv}$ per year [12]. It therefore becomes necessary that care is taken to ensure dose to the lens of the personnel performing interventional procedures with CTF is within recommended limits. Previous studies that investigated doses to the eyes during CTF procedures are based on older CT technologies, and only employed a single kV/mA combination [13-15]. Thus, work is needed to establish radiation reaching the eyes from current CTF technologies.

Two examples of quantities that may be used to quantify radiation exposure are $\mathrm{Hp}(3)$ and entrance surface air kerma (ESAK) [11], the current work uses the latter. ESAK decreases as distance increases [16], and operator's eye position during CTF-guided biopsy varies with radiologist height and head rotation [17]. However, the impact of these factors (height and head rotation) on ESAK to the eye during CTF has not been explored. Therefore, this study aims to investigate ESAK reaching the eyes from a current CT facility during CT fluoroscopy lung biopsy. It also aims to examine the impact of head rotation and radiologist height adjustment on ESAK to the eyes.

\section{MATERIALS AND METHODS}

A 16-slice Toshiba Alexion CT scanner (Toshiba Medical Systems, Nasu, Japan) was used for imaging. Two types of phantoms were used for the study, and comprised of a Lung-man Kyoto phantom (A) simulating the patient and sectional phantom (B) simulating a radiologist. The Lung-man Kyoto phantom (Kyoto Kagaku Co, Kyoto, Japan), comprised of synthetic bones and 
soft tissue material with absorption characteristics similar to the human tissue; this was used to simulate a patient's chest. The phantom was positioned supine on the table and centered at the midline of the couch to simulate actual clinical setting. The horizontal laser beam from the CT scanner was centered to the mid-chest area at the level of the 7 th thoracic vertebrae, which is the typical centering point for a chest CT scan. This has been shown to generate scattered radiation similar to that observed during the actual interventional percutaneous procedures [17].

The sectional phantom (B) simulating the radiologist (phantom radiologist) was made from durable Urethane material and a refurbished human skeleton (The Phantom Laboratory, NY, USA). This phantom radiologist was placed in a position similar to that obtained in the clinical setting (Figure 1). This phantom was positioned erect on the left side of the patient, as it is the side closest to the primary photons. It was placed $100 \mathrm{~cm}$ directly away from the epicenter of the aperture, $50 \mathrm{~cm}$ from the midline of CT couch (x-axis), and $86 \mathrm{~cm}$ down from primary photons (zaxis) as described in previous studies $[17,18]$ and in figure 1 . The selected distances of $50 \mathrm{~cm}$ and $100 \mathrm{~cm}$ have been reported as the positions of the radiologist during the procedure $[17,18]$. The selected distance in the $\mathrm{z}$-axis $(86 \mathrm{~cm})$ was calculated based on the distance from the aperture and $\mathrm{x}$-axis using the Pythagoras theorem. 


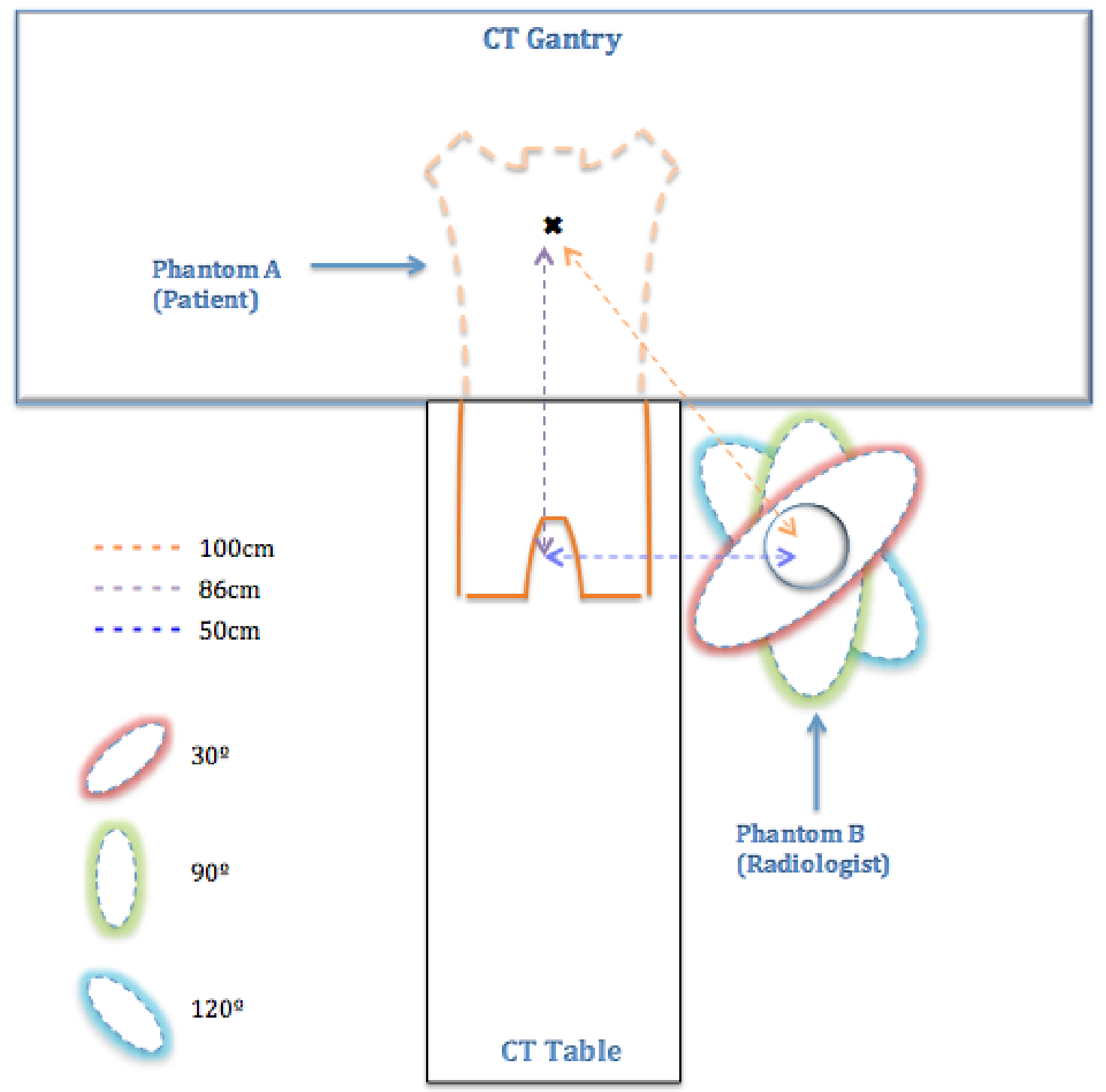

Figure 1: Overview of CTF lung biopsy experimental setting showing angles of rotation of the phantom simulating the radiologist $\left(30^{\circ}, 90^{\circ}\right.$, and $\left.120^{\circ}\right)$ represented by the three ovals. It also shows its distance away from the direct beam $(100 \mathrm{~cm})$ and CT couch $(50 \mathrm{~cm})$, as illustrated by the orange and blue lines.

Exposures were made at three phantom heights $[160 \mathrm{~cm}$ (average female height), $180 \mathrm{~cm}$ (average male height), and $200 \mathrm{~cm}$ (above average height)]. Exposures were also made with the head at three different angles of rotation $\left(30^{\circ}, 90^{\circ}\right.$ and $\left.120^{\circ}\right)$. These were chosen to represent different 
radiologists' angles from the beam: facing the gantry entrance $\left(30^{\circ}\right)$; facing the $\mathrm{CT}$ couch $\left(90^{\circ}\right)$; facing the equipment trolley $\left(120^{\circ}\right)$ (Figure 1). Lead glasses (model 66 economy, Phillips Safety Products, NJ, USA) with side shields was used to cover the eyes of the phantom radiologist. The thickness of the glass lenses (Schott Sf-6-HT) was equivalent to $0.75 \mathrm{~mm}$ of lead. These glasses had adequate spacing to accommodate the Unfors Xi Dosimeter to be placed between it and the phantom's eyes.

A total of 108 exposures were made using the 16-slice Toshiba Alexion CT scanner (Toshiba Medical Systems, Nasu, Japan). The acquisition parameters used were consistent with that used during clinical CT fluoroscopy guided biopsy. Exposures were made and ESAK to the eyes measured with and without lead glasses at two kilovoltages (120 kVps and $135 \mathrm{kVps})$ and three $\mathrm{mA}$ settings $(10 \mathrm{~mA}, 20 \mathrm{~mA}$, and $30 \mathrm{~mA})$. The rotation time was set at 0.75 seconds per 360 degrees at $6 \mathrm{~mm}$ beam width. A calibrated Unfors Xi Dosimeter (RaySafe, Billdal, Sweden) was used to measure the radiation at the phantom radiologist's right eye. Generally, radiation dose to an operator is higher on the side closer to the primary beam. The right eye was chosen as it is closer to the primary beam in with right-handed radiologists.

ESAK to the eyes is regarded as one of the main radiation quantities of concern during CT fluoroscopy and CT interventional procedures [11]. To measure ESAK to the eyes, the Unfors Xi dosimeter was fixed to the eyes of the phantom. For ESAK measurement with lead protection glasses, it was placed over the dosimeter without changing its position. The dosimeter was turned on, and CT dose measurement mode selected. The dosimeter outputted peak entrance surface air kerma (ESAK), which is the maximum radiation delivered to the eye of the personnel performing the CTF lung biopsy. CT dose measurements were repeated 10 times at each setting, 
and then averaged, to minimize the effect of random error.

The Statistical Package for Social Sciences (SPSS) version 21 was used for data analysis. The peak entrance surface air kerma (ESAK) to the eyes were calculated at different $\mathrm{kVps}, \mathrm{mA}$, and phantom radiologist's heights and angles with and without lead glasses. A paired t-test with Bonferroni correction for multiple comparisons was used to compare peak entrance surface air kerma (ESAK) to the eye at different kVps and mAs with and without lead glasses. Peak ESAK to the eye at different heights and angles were also compared with and without lead glasses on the eyes. Statistical significance was two-sided, with a $\mathrm{p}$ value $\leq 0.05$ signifying statistically significant differences between parameters compared.

\section{RESULTS}

Peak entrance surface air kerma (peak ESAK) to the eye with and without lead glasses at different adjustments is presented in figures $1-3$. At all $\mathrm{kVps}$ and $\mathrm{mA}$ combinations and phantom radiologist's heights, peak ESAK to the eyes was significantly higher without lead glasses compared to with lead glasses $(\mathrm{p} \leq 0.001)$. The peak ESAK to the eyes significantly increased as the phantom radiologist rotates toward the gantry without lead glasses, from $2.42 \mu \mathrm{Gy}$ at $120^{\circ}$ to $10.54 \mu \mathrm{Gy}$ at $30^{\circ}(\mathrm{p}=0.001)$. With lead glasses, peak ESAK to the eyes decreased from $4.1 \mu \mathrm{Gy}$ at $120^{\circ}$ to $2.77 \mu \mathrm{Gy}$ at $30^{\circ}(\mathrm{p}=0.001)$. At $120^{\circ}$ rotation away from the gantry, peak ESAK was higher with protective glasses compared to without glasses (Figure 2). The increase in peak ESAK to the eyes with lead glasses at $120^{\circ}$ rotation away from the gantry was consistent across all heights and $\mathrm{kVps}(\mathrm{p} \leq 0.001)$. 


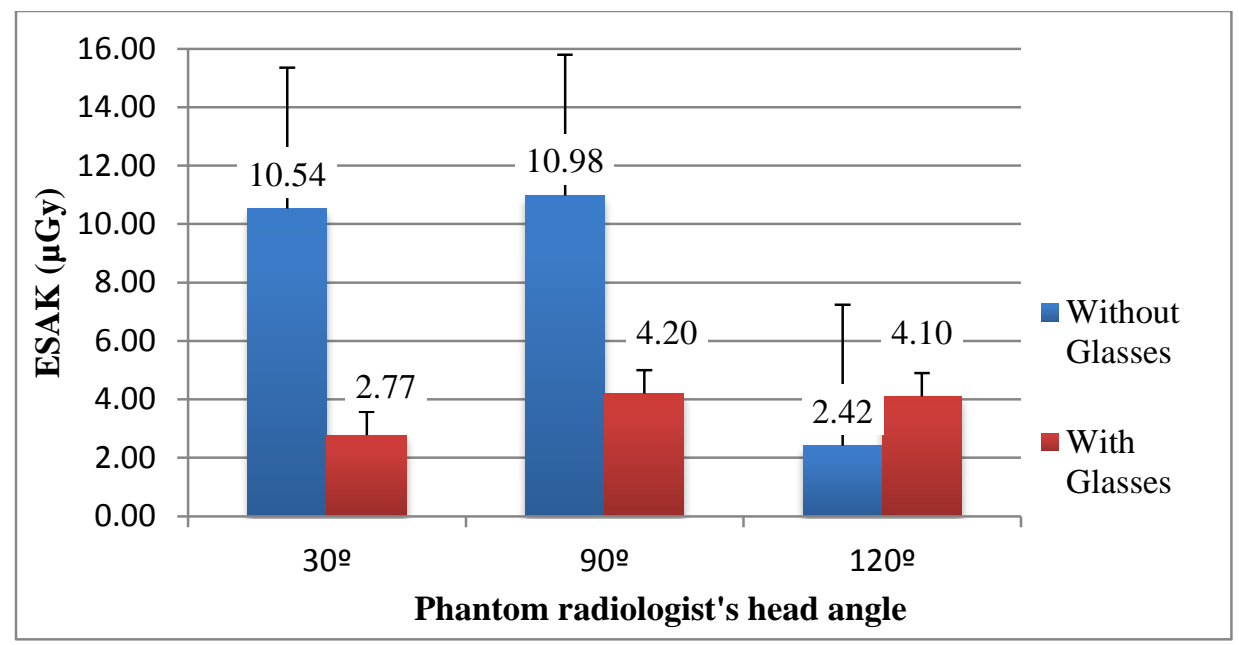

Figure 2: ESAK to the eyes at different phantom radiologist's head angle.

There was no significant change in peak entrance surface air kerma (ESAK) to the eyes with change in phantom radiologist height $(\mathrm{p}>0.05)$ (Figure 3). Without lead glasses, peak ESAK values were $7.51 \mu \mathrm{Gy}, 7.38 \mu \mathrm{Gy}$, and $6.32 \mu \mathrm{Gy}$ at heights of $160 \mathrm{~cm}, 180 \mathrm{~cm}$ and $200 \mathrm{~cm}$ respectively. Similarly, there was no significant difference in ESAK at different phantom radiologist heights with glasses over the eyes $(\mathrm{p}>0.05)$.

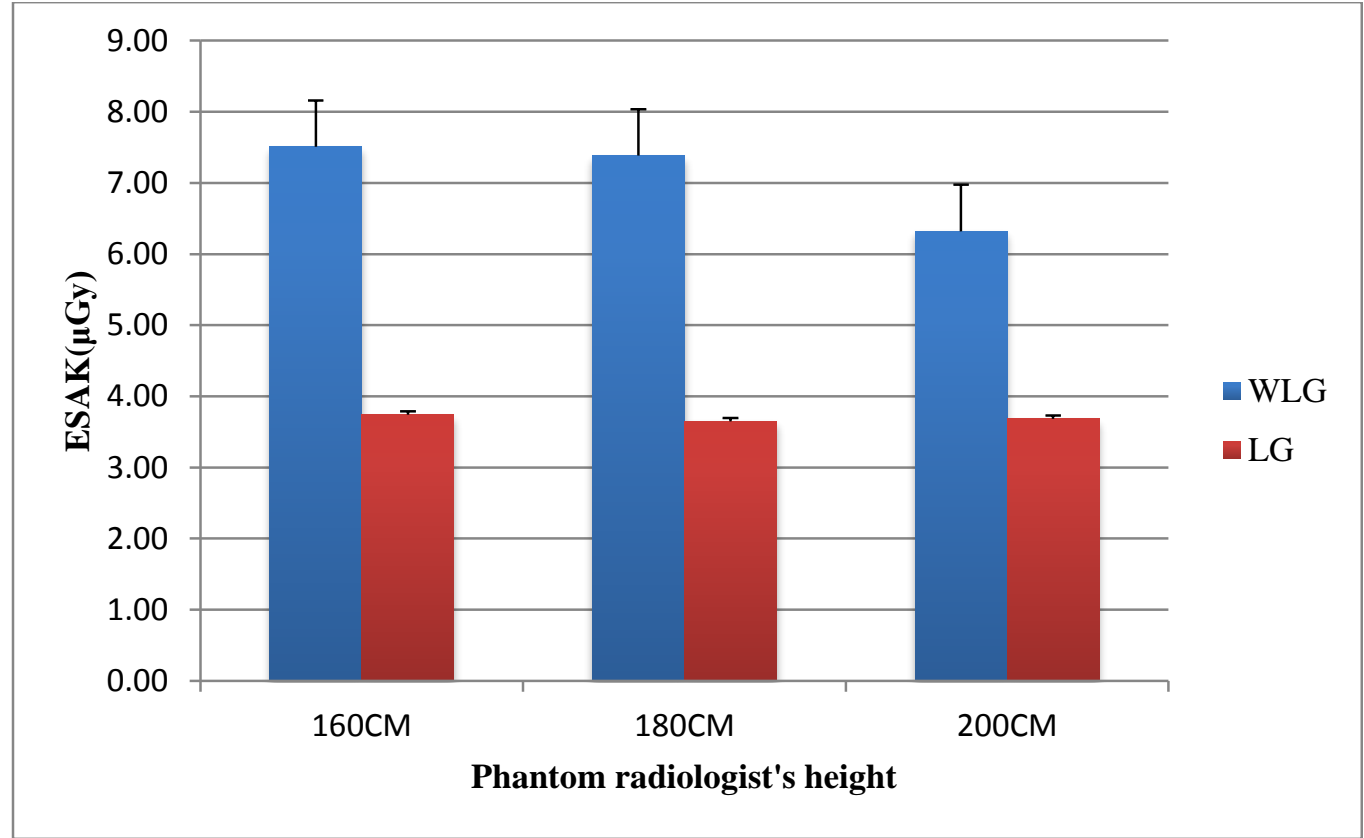

Figure 3: Entrance surface air kerma at different phantom radiologist heights; WLG: without 
lead glasses; LG: with lead glass

Increasing the beam energy from $120 \mathrm{kVp}$ to $135 \mathrm{kVp}$ resulted in a $23 \%$ increase in peak ESAK to the eyes with glasses $(\mathrm{p}=0.001)$. This also resulted in a $26 \%$ increase in peak ESAK without glasses ( $\mathrm{p}=0.001$ ). Similarly, increasing the tube current from $10 \mathrm{~mA}$ to $20 \mathrm{~mA}$ almost doubled eye dose $(\mathrm{p}=0.005)$. A small but significant increase in peak ESAK to the eyes was observed by increasing tube current from $20 \mathrm{~mA}$ to $30 \mathrm{~mA}$ (Figure 4).

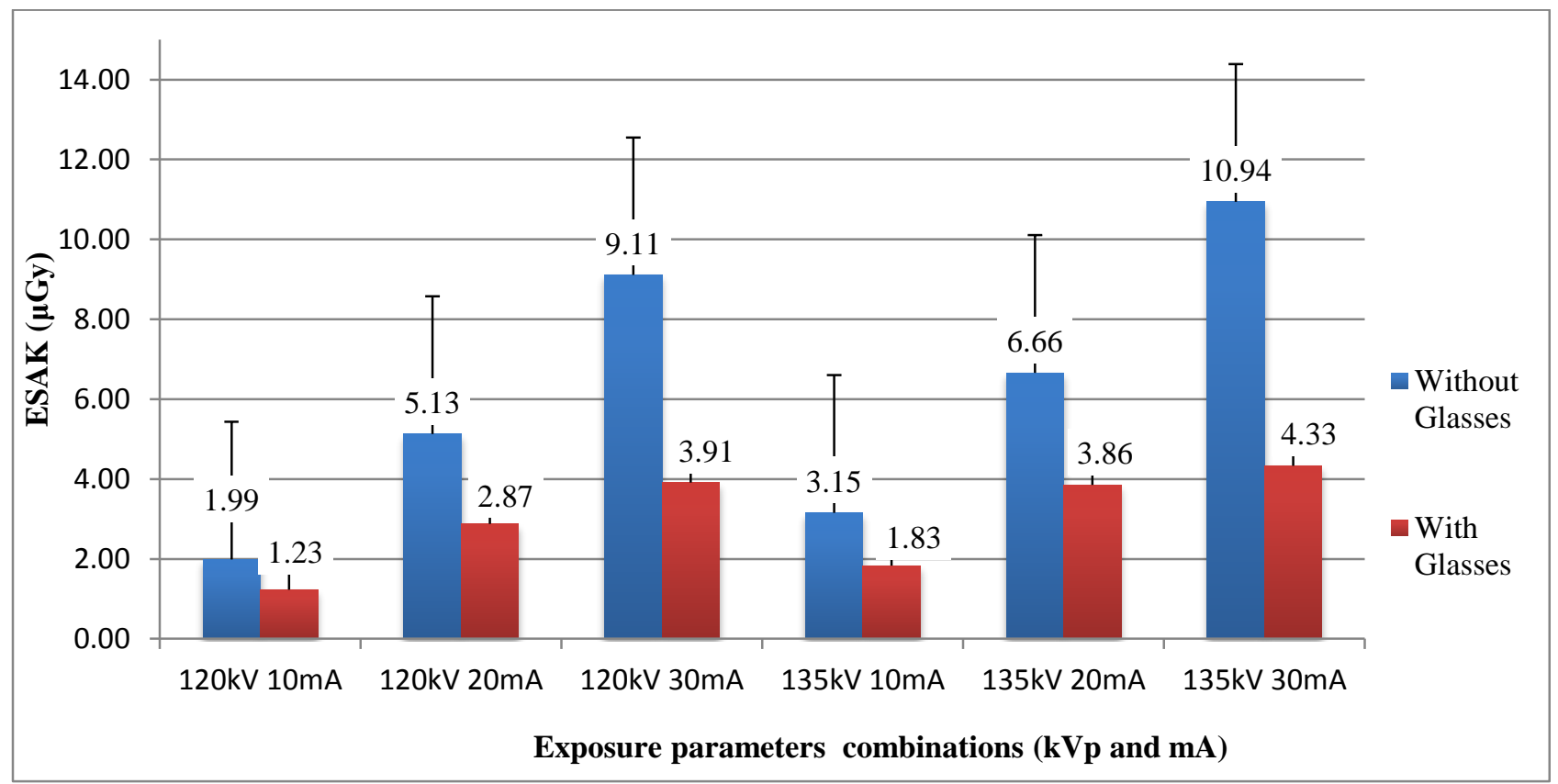

Figure 4: Peak ESAK to the eyes at different $\mathrm{kVps}$ and $\mathrm{mA}$ combinations

\section{DISCUSSION}

The results of this phantom-based experiment demonstrate that lead glasses, and head rotation away from the gantry significantly reduce dose reaching the lens of the interventionist during CT fluoroscopy lung biopsy. Findings also demonstrate higher lens doses with increasing exposure 
parameters, but no significant dose difference with change in the height of the interventionist.

Radiation reaching the eye lens constitutes one of the greatest risks to the CTF interventionists [11]. Lens doses reported without protective glasses per interventional procedure ranged from $0.25-34.5 \mathrm{mSv}[7,19]$. As the current annual dose limit for the eye is $50 \mathrm{mSv}$ per year, the potential high dose from this procedure emphasizes the need for lens protection. The current study shows that lead glasses reduce ESAK to the lens by half. Our finding agrees with previous studies that have reported 2.73 - 5 fold dose reductions with protective lead glasses during interventional procedures $[20,21]$. The current study also demonstrates that in the absence of lead glasses, head rotation away from the gantry during exposure significantly reduces dose to the eye by a factor of five. This is illustrated by the fact that the dose values without glasses at $120^{\circ}(2.24 \mu \mathrm{Gy})$ and with glasses at $30^{\circ}(2.77 \mu \mathrm{Gy})$ are comparable. It is logical that since scattered radiation travels in an angular fashion, fewer X-ray photons may reach the lens when the head is rotated $120^{\circ}$ away from the direction of scatter. It is clear that lens dose was higher with lead glasses compared to without lead glasses at $120^{\circ}$ head position. We hypothesize that this was due to backscatter from the glasses towards the lens. This phenomenon will be further investigated using Monte-Carlo simulation in the future.

Some imaging systems are equipped with the Combined Applications to Reduce Exposure (CARE) system to minimize lens doses by reducing exposure when the tube is at 10:00 and 2:00 o'clock positions [22]. Beam angulation and lead drapes have also been shown to reduce dose to the lens [7, 21, 23]. Hohl et al. [23] reported that scattered and primary radiation to the interventionist's eye was reduced by $27 \%$ and $72 \%$ respectively with tube angulation. A 12 -times dose reduction has been reported using lead drapes [21], another study demonstrated that drapes placed 10 and $60 \mathrm{~cm}$ from the scanning plane reduced scattered radiation to the operator by $71 \%$ 
and $14 \%$ respectively [7].

Optimisation is paramount in any radiological procedure in order to produce high quality images at appropriate radiation doses; therefore exposure parameter selection is critical to optimisation [24]. Changes in $\mathrm{kVp}$ and $\mathrm{mA}$ are known to have direct influence on radiation dose $[25,26]$. Increasing $\mathrm{mA}$ alone has been shown to be associated with noise reduction, meaning improvement in image quality [27]. There is a variety of tube voltages $(\mathrm{kVp})$ and tube current (mA) combinations used for CT fluoroscopy-guided biopsy procedures. Nonetheless, the impact of changes in $\mathrm{kVp} / \mathrm{mA}$ combinations on radiation reaching the eyes during $\mathrm{CT}$ fluoroscopy has not been investigated. Previous studies $[13,14]$ only employed a single $\mathrm{kVp} / \mathrm{mA}$ combination to assess radiation reaching the eyes during CT fluoroscopy. One of these studies recommended starting CT fluoroscopy screening at $120 \mathrm{kV}$ and $10 \mathrm{~mA}$ exposure parameter combinations, then increasing to $135 \mathrm{kV}$ and $10 \mathrm{~mA}, 120 \mathrm{kV}$ and $20 \mathrm{~mA}$, and $135 \mathrm{kV}$ and $20 \mathrm{~mA}$, as may be necessary. The current study assessed peak ESAK at each of the recommended exposure levels and shows that increased $\mathrm{kVp}$ and $\mathrm{mA}$ increases ESAK to the eye and that for a given $\mathrm{kVp}$, ESAK increases with increased mA. Thus, it is important for the lowest exposure parameter combinations providing optimum image quality be employed for CT fluoroscopy lung biopsy, thus ensuring risk to the interventionist is as low as reasonably achievable.

The dose from ionizing radiation is inversely proportional to the distance from its source due to the inverse square law [16]. Therefore, it is intuitive that increasing the height of the phantom simulating the radiologist and thus the distance between its head and scattered radiation from the patient may lower ESAK to its eyes. An important observation in the current study is that as the height of the phantom simulating the radiologist was increased, there was no significant decrease 
in ESAK reaching its eyes. The difference in ESAK between $160 \mathrm{~cm}$ and $200 \mathrm{~cm}$ at $30^{\circ}$ and $90^{\circ}$ with and without glasses was also non-significant. This finding suggests that risk to the lens of the eyes from CT fluoroscopy lung biopsy procedures may be the same regardless of the height of personnel.

Previous studies assessing lens dose from older CT technologies such as Somatom Plus 4 CTscanner (Siemens Medical Systems) and CT/i; (GE Medical Systems) used quantities such as dose rates, dose equivalent, and entrance surface dose to quantify lens dose. Lens doses reported from these systems ranged from $0.17 \mathrm{mSv}$ to $0.762 \mathrm{mSv}[28,29]$, with dose rates ranging from 2.3 to $10.4 \mathrm{mGy} / \mathrm{sec}$ [7]. Lens doses without lead glasses reported from seven interventional radiology fluoroscopic systems ranged from $0.006 \mathrm{mSv}$ to $0.0345 \mathrm{mSv}$ [19]. The current study focused on lens doses (ESAK) during lung biopsy using a 16-slice Toshiba Alexion CT scanner, and the highest lens dose recorded was $0.0189 \mathrm{mGy}(0.0189 \mathrm{mSv})$, which is lower than that reported for older CT technologies.

The 16-slice Toshiba Alexion CT scanner used in the current work employs a faster readout detector with a wider dynamic range compared to CT technologies used in previous works [13, 14]. Thus, the current work provides data on ESAK to the eyes from CT fluoroscopy technologies currently in clinical use. The safety time limit for the radiologist's eye reported by previous works is based on the 1990 ICRP recommendations of $150 \mathrm{mSv}$. The revised ICRP recommendation (maximum of $50 \mathrm{mSv}$ per year) underscores the need for assessment of safety time limits for new CT fluoroscopy systems. Based on the ESAK values obtained in the current work and the new ICRP recommendations, maximum safety times with and without glasses of 37.02 hours and 19.83 hours respectively, are appropriate for the CT fluoroscopy interventionists. The reported mean CT fluoroscopy time per procedure for each interventionist 
ranged from 4.8 to 143 seconds [30]. Assuming the worst case scenario (143 seconds), the maximum number of procedures using the 16-slice Toshiba Alexion scanner would be 932 and 500 procedures, equating to approximately 4 and 2 procedure per day, with and without lead glasses respectively.

$\mathrm{Hp}(3)$ is the operational quantity recommended for the monitoring exposure to the eye lens at a depth of $3 \mathrm{~mm}$, in a phantom that mimics the absorption and scattering characteristics of the head. As a slab phantom is not always suitable for $\mathrm{Hp}(3)$ measurement at high angles, a cylindrical phantom has been developed. Conversion coefficient between air kerma and $\mathrm{Hp}(3)$ for this phantom has been published for different beam qualities [31]. The current work obtained results using ESAK and compared the dose to the eyes at different $\mathrm{kVp}$ settings and operator head angles. Future work could perhaps use both ESAK and $\mathrm{Hp}(3)$ to enable comparisons.

A limitation of the current work is that the results are specific to the lung biopsy scenario; other interventional procedure such as liver biopsy would result in higher doses. Thus, further work is required to explore radiation risk to the eyes from such procedures. Conversely, the strengths of the work include that the Unfors Xi Dosimeter used is highly sensitive to low levels of radiation such as scatter or leakage, with a response time of 0.5 seconds. These characteristics make it suitable for measuring a wide range of energies. Thus, data produced in the current study is representative of ESAK to the lens during CT fluoroscopy lung biopsy.

\section{CONCLUSION}

Data produced demonstrates that lead glasses significantly reduce ESAK to the eyes during CT fluoroscopy. Findings also show that angle of the interventionist's head relative to the gantry 
impacts upon ESAK to the eyes.

\section{REFERENCES}

1. Ekpo EU and McEntee MF, An Evaluation of Performance Characteristics of Primary Display Devices. J Digit Imaging. 29: 2015, 175-182.

2. Alfidi RJ, Haaga J, Meaney TF, MacIntyre WJ, Gonzalez L, Tarar R, Zelch MG, Boller M, Cook SA and Jelden G, Computed tomography of the thorax and abdomen; $a$ preliminary report. Radiology. 117(2),1975,257-264.

3. Haaga JR and Alfidi RJ, Precise biopsy localization by computed tomography. Radiology. 118(3),1976,603-607.

4. Sarti M, Brehmer WP and Gay SB, Low-dose techniques in CT-guided interventions. Radiographics. 32(4),2012,1109-1119.

5. Katada K, Anno H, Takeshita G, Ogura Y, Koga S, Ida Y, Nonomura K, Kanno T, Ohashi A and Sata S, Development of real-time CT fluoroscopy. Nihon Igaku Hōshasen Gakkai zasshi. Nippon acta radiologica. 54(12),1994,1172-1174.

6. Prosch H, Stadler A, Schilling M, Bürklin S, Eisenhuber E, Schober E and Mostbeck G, CT fluoroscopy-guided vs. multislice CT biopsy mode-guided lung biopsies: Accuracy, complications and radiation dose. European Journal of Radiology. 81(5),2012,10291033.

7. Nawfel RD, Judy PF, Silverman SG, Hooton S, Tuncali K and Adams DF, Patient and personnel exposure during CT fluoroscopy-guided interventional procedures. Radiology. 216(1),2000,180-4.

8. Hendrick RE, Radiation doses and cancer risks from breast imaging studies. Radiology. 257(1),2010,246-53.

9. Irie T and Kuramochi M, Newly developed application system for CT-guided puncture based on multidetector row CT without CT fluoroscopy. Radiation Medicine - Medical Imaging and Radiation Oncology. 25(8),2007,411-416.

10. Stoeckelhuber BM, Leibecke T, Schulz E, Melchert UH, Bergmann-Koester CU, Helmberger $\mathrm{T}$ and Gellissen $\mathrm{J}$, Radiation dose to the radiologist's hand during 
continuous CT fluoroscopy-guided interventions. CardioVascular and Interventional Radiology. 28(5),2005,589-594.

11. Aviles Lucas P, Dance DR, Castellano IA and Vano E, Estimation of the peak entrance surface air kerma for patients undergoing computed tomography-guided procedures. Radiat Prot Dosimetry. 114(1-3),2005,317-20.

12. Stewart FA, et al., ICRP PUBLICATION 118: ICRP Statement on Tissue Reactions and Early and Late Effects of Radiation in Normal Tissues and Organs - Threshold Doses for Tissue Reactions in a Radiation Protection Context. Annals of the ICRP. 41(1-2),2012,1322.

13. Kato R, Katada K, Anno H, Suzuki S, Ida Y and Koga S, Radiation protection in CT fluoroscopy. Seminars in Interventional Radiology. 16(3),1999,167-174.

14. Buls N, Pagés J, De Mey J and Osteaux M, Evaluation of patient and staff doses during various CT fluoroscopy guided interventions. Health Physics. 85(2),2003,165-173.

15. ICRP, 1990 Recommendations of the International Commission on Radiological Protection. Annals of the ICRP. 21(1-3),1991,1-201.

16. Harding LK, Harding NJ, Warren H, Mills A and Thomson WH, The radiation dose to accompanying nurses, relatives and other patients in a nuclear medicine department waiting room. Nucl Med Commun. 11(1),1990,17-22.

17. Mahnken AH, Sedlmair M, Ritter C, Banckwitz R and Flohr T, Efficacy of lower-body shielding in computed tomography fluoroscopy-guided interventions. CardioVascular and Interventional Radiology. 35(6),2012,1475-1479.

18. Silverman SG, Tuncali K, Adams DF, Nawfel RD, Zou KH and Judy PF, CT fluoroscopy-guided abdominal interventions: Techniques, results, and radiation exposure. Radiology. 212(3),1999,673-681.

19. Vano E, Gonzalez L, Fernandez JM and Haskal ZJ, Eye lens exposure to radiation in interventional suites: caution is warranted. Radiology. 248(3),2008,945-53.

20. Sans Merce M, Korchi AM, Kobzeva L, Damet J, Erceg G, Marcos Gonzalez A, Lovblad $\mathrm{KO}$ and Mendes Pereira V, The value of protective head cap and glasses in neurointerventional radiology. J Neurointerv Surg.2015. doi:10.1136/neurintsurg- 2015011703 
21. Thornton RH, Dauer LT, Altamirano JP, Alvarado KJ, St Germain J and Solomon SB, Comparing strategies for operator eye protection in the interventional radiology suite. $J$ Vasc Interv Radiol. 21(11),2010,1703-7.

22. Booij R. New applications and technology in DSCT: How to take full advantage (3/3) CARE. 2012 [cited 2016 14/03]; Available from: http://www.dsct.com/index.php/newapplications-and-technology-in-dsct-how-to-take-full-advantage-23-care/.

23. Hohl C, Suess C, Wildberger JE, Honnef D, Das M, Muhlenbruch G, Schaller A, Gunther RW and Mahnken AH, Dose reduction during CT fluoroscopy: phantom study of angular beam modulation. Radiology. 246(2),2008,519-25.

24. Ekpo EU, Hoban AC and McEntee MF, Optimisation of direct digital chest radiography using Cu filtration. Radiography. 20(4),2014,346-350.

25. McNitt-Gray M, AAPM/RSNA Physics Tutorial for Residents: Topics in CT: Radiation Dose in CT1. Radiographics. 22(6),2002,1541-1553.

26. Egbe NO, Egong EA, Ekpo EU and Inah GB, A reduction in radiographic exposure and image quality in film screen postero-anterior chest radiography. Niger $J$ Med. 21(1),2012,21-4.

27. Yamao Y, Yamakado K, Takaki H, Yamada T, Murashima S, Uraki J, Kodama H, Nagasawa N and Takeda K, Optimal Scan Parameters for CT Fluoroscopy in Lung Interventional Radiologic Procedures: Relationship between Radiation Dose and Image Quality1. Radiology. 255(1),2010,233-241.

28. Buls N, Pages J, de Mey J and Osteaux M, Evaluation of patient and staff doses during various CT fluoroscopy guided interventions. Health Phys. 85(2),2003,165-73.

29. Ciraj-Bjelac O, Antic V, Selakovic J, Bozovic P, Arandjic D and Pavlovic S, Eye lens exposure to medical staff performing electrophysiology procedures: dose assessment and correlation to patient dose. Radiat Prot Dosimetry.2016. doi:10.1093/rpd/ncv552

30. Silverman SG, Tuncali K, Adams DF, Nawfel RD, Zou KH and Judy PF, CT fluoroscopy-guided abdominal interventions: techniques, results, and radiation exposure. Radiology. 212(3),1999,673-81.

31. Principi S, Guardiola C, Duch MA and Ginjaume M, Air kerma to $h p(3)$ conversion coefficients for IEC 61267 RQR x-ray radiation qualities: application to dose monitoring 
of the lens of the eye in medical diagnostics. Radiat Prot Dosimetry.2015. doi:10.1093/rpd/ncv435 